\title{
Assessing the Adequacy of the Simulation Model LATEBLIGHT Under Nicaraguan Conditions
}

Jorge Ulises Blandón-Díaz, Department of Plant and Forest Protection, National University of Agriculture (UNA), Managua, Nicaragua, Apdo. 453, and Department of Forest Mycology and Pathology, Swedish University of Agricultural Sciences, S-750 07 Uppsala, Sweden; Gregory A. Forbes, International Potato Center (CIP), Lima 12, Peru; Jorge L. Andrade-Piedra, CIP, Quito, Ecuador; and Jonathan E. Yuen, Department of Forest Mycology and Pathology, Swedish University of Agricultural Sciences

\begin{abstract}
Blandón-Díaz, J. U., Forbes, G. A., Andrade-Piedra, J. L., and Yuen, J. E. 2011. Assessing the adequacy of the simulation model LATEBLIGHT under Nicaraguan conditions. Plant Dis. 95:839-846.

In this study, the adequacy of the late blight simulation model LATEBLIGHT (version LB2004) was evaluated under Nicaraguan conditions. During 2007 to 2008, five field experiments were conducted in three potato-production regions in northern Nicaragua. Two susceptible ('Cal White' and 'Granola') and one resistant ('Jacqueline Lee') potato cultivars were evaluated without use of fungicides and with three application intervals $(4,7$, and 14 days) of the fungicide chlorothalonil. The simulation model was considered adequate because it accurately predicted high disease severity in susceptible cultivars without fungicide

protection, and demonstrated a decrease in the disease progress curves with additional fungicide applications, similar to that observed in the plots. The model also generally predicted inadequate fungicide control, even with a 4-day spray interval, which also occurred in the field. Lack of adequate fungicide protection would indicate the need for cultivars with higher levels of durable resistance, and that farmers should consider more effective fungicides applications (higher dosages or different chemistries) if susceptible cultivars are used.
\end{abstract}

The oomycete pathogen Phytophthora infestans, causal agent of potato late blight and a major factor in Ireland's potato famine of the nineteenth century, is a destructive organism which is widely distributed on potato and tomato crops around the world $(7,17)$. Strategies for managing late blight generally involve frequent fungicide applications and, therefore, often bring into question their sustainability based on economic and environmental considerations (20,28). In developing countries (including Nicaragua), potato growers sometimes cannot afford fungicides, or otherwise do not adequately use them, which results in high disease severity, substantial crop losses, and, sometimes, crop abandonment $(19,25)$.

Field studies have shown the usefulness of combining resistant cultivars and protectant fungicides such as mancozeb and chlorothalonil for late blight control $(11,19,21)$. Nevertheless, the determination of the number and frequency of applications of fungicides for a specific cultivar-location combination is a difficult task because it may require multiple field experiments due to the great variation in weather among locations and potential different levels of host resistance (24). Computerized models for disease simulation can be effective tools in the evaluation of strategies for disease control because they allow preliminary assessment of a number of scenarios involving many variables, including weather conditions, level of host resistance, and aggressiveness or virulence of the local pathogen population $(2,29)$. Disease simulation can thus reduce research costs, because only the most promising strategies would be evaluated in the field $(29,30)$.

Initially, the LATEBLIGHT simulation model was used to investigate the effect of rate-reducing resistance on the performance of the protectant fungicide chlorothalonil sprayed at fixed intervals (9). Later, an improved version of LATEBLIGHT (version LB1990) was used to examine several strategies involving the

Corresponding author: J. U. Blandón-Díaz,

E-mail: ulises.diaz.blandon@mykopat.slu.se

Accepted for publication 10 March 2011.

doi:10.1094/PDIS-10-10-0702

(C) 2011 The American Phytopathological Society fungicides metalaxyl and chlorothalonil for late blight control and delay of metalaxyl resistance development in pathogen populations (13). Details of the model components and descriptions of how simulations are conducted have been described $(3,8,9,13,18)$. The most recent version of the simulation model LATEBLIGHT, LB2004, was developed and validated by Andrade-Piedra et al. (3). The epidemiological parameters were measured in three Peruvian cultivars infected with isolates of the EC-1 clonal lineage of $P$. infestans, which is dominant in Peru and the northern Andes (17). In that study, the authors only simulated disease in nontreated plots (3). The fungicide submodel published by Bruhn and Fry (10) did not give satisfactory results with the data from Peru (unpublished data). The LB2004 version was subsequently used successfully with data from several locations worldwide but, again, without fungicide applications (1).

Given the need for more effective management strategies in Nicaragua, we proposed that the LB2004 version of LATEBLIGHT could be a useful tool for initial evaluation of disease management scenarios. However, it was not known whether the model would work under Nicaraguan conditions, either because the epidemiological parameters used by Andrade-Piedra et al. (2) would not be appropriate for the Nicaraguan cultivars and pathogen population or for other, undetermined, reasons. We also proposed to evaluate the appropriateness of a modified version of the fungicide submodel.

One additional problem associated with the management of late blight in developing countries is the absence of a system for quantifying host resistance. Recently, a simple scale was proposed for quantifying susceptibility that is putatively robust across locations (35); thus, another aim of the current study was to apply the new scale to the cultivars used in the experiments: two local susceptible cultivars and one introduced resistant cultivar. The experiments were designed to allow quantification of cultivar resistance and evaluate the efficacy of different fungicide-regime-cultivar combinations. The experiments were also used to evaluate the appropriateness of the LB2004 for use in Nicaragua. The specific objectives were to (i) evaluate the adequacy of LATEBLIGHT (version LB2004) for disease management scenario testing under Nicaraguan conditions, (ii) quantify the degree of susceptibility to $P$. infestans in three potato cultivars grown in Nicaragua, and (iii) 
compare three application intervals of the contact fungicide chlorothalonil for disease management with these cultivars.

\section{Materials and Methods}

Field trials. The experiments were implemented in two potatogrowing regions in northern Nicaragua (Table 1), and included two susceptible ('Cal White' and 'Granola') and one resistant ('Jacqueline Lee') cultivars, the latter of which was recently introduced to Nicaragua. All three had a vegetative cycle lasting 90 to 110 days under Nicaraguan conditions. Cal White and Granola were both known to be susceptible to P. infestans, while Jacqueline Lee was considered to be resistant to the US-8 strain in the United States $(14,33)$. However, quantitative information on the degree of resistance was not known for any of the cultivars.

Whole tubers of these cultivars were planted on 15, 16, and 20 November 2007 in El Arenal, Miraflor, and Tisey, respectively, and on 3 and 17 July 2008 in Tisey and Miraflor, respectively. Experimental plots were $4.5 \mathrm{~m}$ long by $4 \mathrm{~m}$ wide (four rows per plot and 15 plants per row) and each of these represented an experimental unit. Each cultivar was tested without fungicides and with three fungicide spray regimes (described below). Treatments (cultivarfungicide-regime combinations) were arranged in a randomized complete block design and replicated four times. Plots were separated from each other by $2 \mathrm{~m}$ of fallow soil. Fertilizers and nonexperimental pesticide sprays were applied in accordance with the grower practices at each of the three locations. At planting, di-ammonium phosphate $[18(\mathrm{~N})-46(\mathrm{P})-0(\mathrm{~K})]$ was applied at $318 \mathrm{~kg} / \mathrm{ha}$ together with terbufos (Counter 10G) at $1 \mathrm{~kg}$ a.i./ha. Weeds were managed with metribuzin at $700 \mathrm{~g}$ a.i./ha when needed. The plants were hilled and fertilized again with urea ( $\mathrm{N}$ at $60 \mathrm{~kg} / \mathrm{ha}) 38$ days after planting.

Fungicide applications. These consisted of three application intervals of the fungicide chlorothalonil (Knight $72 \mathrm{SC}, 720 \mathrm{~g}$ a.i./liter). Fungicide applications were initiated for a particular cultivar-location combination when percent emergence was at $50 \%$. The first date of fungicide application was considered as the date of crop emergence and was used in the simulations (below). After the first fungicide application, plots were sprayed every 4, 7, or 14 days, depending on treatment. The fungicide chlorothalonil (Knight $72 \mathrm{SC}$ ) was applied at the recommended rate of $1.5 \mathrm{li}-$ ters/ha and ensuring a concentration of $2.52 \mathrm{~g}$ a.i./liter of water. Plots without fungicide application were left as nontreated controls. Overall, there were five experiments, because one of the three locations (Arenal) was not repeated in 2008; thus, with four spray regimes (including the nontreated control) there were, in total, 20 epidemics per cultivar. Results for disease progress and simulations are not presented for Jacqueline Lee for reasons given below.

Disease assessment and weather measurements. Percent disease severity was estimated visually once a week, starting 1 to 2 days after $50 \%$ plant emergence using a late blight standard area diagram (6), which had been modified by Fry (15). Estimates of disease severity were made in 30 plants of the two central rows of each experimental plot. Disease severity assessments ended when severity in the majority of the nontreated plots of susceptible culti- vars reached $100 \%$. Severity values from each plot were converted to the area under the disease progress curve (AUDPC) using the midpoint method (12), and then to the relative AUDPC (RAUDPC; 16). To evaluate the level of susceptibility of the three cultivars to $P$. infestans, the RAUDPC was converted to susceptibility scale values as described by Yuen and Forbes (35). Briefly, the susceptibility scale is based on ascending numbers (1 to 9) representing increasing susceptibility and can use either a one-reference cultivar or two-reference cultivar model to convert disease measures [e.g., AUDPC and RAUDPC] into susceptibility scale values. Moreover, this susceptibility scale was considered by Yuen and Forbes (35) to be a ratio scale and, thus, appropriate for statistical analyses. For this purpose, Cal White, known to be susceptible to P. infestans (33), was assigned a value of 8 , which was then used to calculate the other values. Scale values were calculated from the mean RAUDPC value of each cultivar, estimated in the nontreated plots.

Air temperature and relative humidity were measured using data loggers equipped with sensors (HOBO U23 Pro v2 Temp/HR; Onset Computer Corporation, Pocasset, MA), protected in wooden meteorological shelters placed $1.5 \mathrm{~m}$ above the soil. Rainfall was measured with an automated tipping bucket rain gauge (RG3-M, HOBO; Onset Computer Corporation) placed above the potato canopy $(1.2 \mathrm{~m})$. All sensors were sampled at 15 -min intervals. Hourly averages were calculated to enable estimation of hours during which relative humidity was $>85 \%$ (3).

Simulation and parameterization. Simulations were performed with the LB2004 version of model LATEBLIGHT (2). Initially, the parameters derived by Andrade-Piedra et al. (2) for the susceptible Peruvian cultivar 'Tomasa' were evaluated in simulations with the epidemic data from Nicaragua for use with the two susceptible cultivars Cal White and Granola but the results were not satisfactory. Therefore, modifications were made in the lesion growth rate (LGR) and the sporulation rate (SR) of the parameters from Tomasa. The modifications were made by visually fitting simulated and observed disease progress curves. The day of initiation of the epidemic and the number of initial lesions were determined by the method used by Andrade-Piedra et al. (3). It was evident from the disease severity data that Jacqueline Lee was protected by a major resistance $(R)$ gene and primarily had a hypersensitive resistance reaction. For this reason, it was eliminated from the simulation process.

Fungicide efficacy submodel. The original fungicide efficacy submodel for LATEBLIGHT was developed and validated by Bruhn and Fry (9-11) specifically for chlorothalonil. In that model, an average fungicide effect was calculated from the individual effects of the fungicide residues distributed among four levels in the canopy according to a $\gamma$ distribution $(10,11)$. We employed a simplified version in which there was no longer an effect of canopy level. For our model, fungicide was assumed to be applied evenly on foliage. We believe that this was justified because we have observed that farmers using backpack sprayers tend to spray around the plant to achieve even coverage. The average level of deposition for foliage was estimated based on the concentration of the fungicide in the spray solution and a residue factor that indicated the

Table 1. Geographic location, disease onset, temperature, and humid hours of field trials done in northern Nicaragua to test host resistance in potato to Phytophthora infestans and efficacy of different fungicide application frequencies

\begin{tabular}{|c|c|c|c|c|c|}
\hline \multirow[b]{2}{*}{ Location, year } & \multicolumn{3}{|c|}{ Disease onset (days after emergence) } & \multicolumn{2}{|c|}{ Weather variablesw } \\
\hline & Cal White & Granola & Jacqueline Lee & $\mathbf{T}$ & H_hr \\
\hline Arenal $2007^{x}$ & 11 & 11 & 21 & 17.1 & 17.3 \\
\hline Miraflor $2007^{y}$ & 8 & 11 & 30 & 16.2 & 18.9 \\
\hline Tisey $2007^{z}$ & 17 & 20 & 30 & 16.3 & 16.2 \\
\hline Miraflor 2008 & 8 & 12 & 26 & 19.1 & 19.5 \\
\hline Tisey 2008 & 10 & 17 & 25 & 18.1 & 19.9 \\
\hline Average & 11 & 14 & 26 & $\ldots$ & $\ldots$ \\
\hline
\end{tabular}

${ }^{\mathrm{w}} \mathrm{T}=$ mean daily air temperature and $\mathrm{H} \_\mathrm{hr}=$ hours per day of relative humidity $>85 \%$.

x Arenal 2007: latitude $13^{\circ} 02^{\prime} 13^{\prime \prime} \mathrm{N}$, longitude $85^{\circ} 55^{\prime} 03^{\prime \prime} \mathrm{W}$, and 1,380 meters above sea level (masl).

y Miraflor 2007-2008: latitude $13^{\circ} 15^{\prime} 59^{\prime \prime} \mathrm{N}$, longitude $86^{\circ} 16^{\prime} 44^{\prime \prime} \mathrm{W}$, and 1,390 masl.

z Tisey 2007-2008: latitude $12^{\circ} 59^{\prime} 36^{\prime \prime} \mathrm{N}$, longitude $86^{\circ} 22^{\prime} 07^{\prime \prime} \mathrm{W}$, and 1,450 masl. 
amount of water that remains on the potato leaf surface when foliage is sprayed until run-off. A value of $0.0068 \mathrm{~cm}^{3}$ of water per square centimeter of leaf was used for the residue factor (34).

After deposition, the residual amount of fungicide was modified by two degradation factors, temperature and rainfall, given by the following equations (11).

For average daily temperatures below $25.2^{\circ} \mathrm{C}$ (appropriate for all locations in our study):

Temperature_effect $=\min \{1, \exp [-0.043 \times(\operatorname{Tmp}-15.5)]\}($ eq. 1$)$

where $\mathrm{Tmp}=$ average daily temperature $\left({ }^{\circ} \mathrm{C}\right)$;

for rainfall:

Rain_effect $=\exp \{-1.091 \times[$ Rainfall $* *(1 / 3)]+0.313 \times[($ DSPS $\times$ Rainfall $)^{* *(1 / 3)]\}}$

where Rainfall $=$ daily precipitation in centimeters and DSPS $=$ days since previous spray.

Both equations come from Bruhn and Fry (11), who give more information for extreme temperature conditions. Using the equations above, the amount of fungicide on a leaf surface at any time (Fungicide_residue) was equal to:

Fungicide_residue $\left({ }_{t}\right)=$ Fungicide_residue $\left({ }_{t-1}\right) \times$ Temperature_effect $\times$ Rain_effect,

where Fungicide_residue $\left.{ }_{t}\right)=$ fungicide residues on the leaf surface at time $t$.

(eq. 3)

The fungicide model used a simple dose/response curve, estimated by a logistic curve, to estimate a protectant fungicide effect (Prot_eff), and defined by the following equation:

Prot_eff $=1-\left\{\exp \left[\log _{10}(\right.\right.$ Fungicide_residue $\left.\left.)+4.5\right]\right\} /\left\{\exp \left[\log _{10}\right.\right.$ (Fungicide_residue) $]+100\}$ (eq. 4)

Parameter 4.5 of equation 4 was determined by calibration. The fungicide effects disease development by reducing the probability of infection, and protection diminishes as Prot_eff approaches 1.

Model adequacy. The adequacy of the model was investigated in several ways. Initially, observed and simulated disease progress curves were compared graphically to evaluate the fit between observed and predicted data of disease progress with and without fungicides, and the overall pattern of disease severity relative to increasing fungicide application. The efficacy of the fungicide submodel was further evaluated by examining the number of cases when simulation falsely predicted control (false positive) or falsely predicted the absence of control (false negative). Control was arbitrarily defined to occur when final disease severity did not surpass $20 \%$ (22). The simulator was also evaluated based on the deviations between observed and predicted AUDPC values. Deviations were compared with an envelope of acceptance test (EAT), the boundaries for which are calculated from the error of the observed values (23). The relationship between fungicide application and disease development measured by the AUDPC was explored with regression analysis, using the REG procedure of SAS (version 9.1; SAS Institute, Cary, NC). The quadratic regression equation provided the best fit for the relationship between the AUDPC and the fungicide spray interval.

Cultivars were compared for RAUDPC values within each location-year combination using the least significant difference test following an analysis of variance using PROC analysis of variance of SAS v.9.1 (27). Normality of distributions and homogeneity of variances of experimental errors were tested as described by Quinn and Keough (26).

\section{Results}

Relationship between disease onset, severity, and weather. Disease onset varied across experiments and between the two susceptible cultivars, with a range of initiation times from 8 to 20 days after emergence. On average, disease onset was detected earliest (11 days) in Cal White, with Granola taking a few days more (14 days on average). Based on both average temperature and number of hours above $85 \%$ relative humidity (H_hr), 2008 was a warmer and wetter year although, in 2007, H_hr was somewhat higher (18.9) in Miraflor than in the other locations (Table 1). These weather parameters characterized highly disease-conducive conditions because disease progressed rapidly in all experiments in Cal White and Granola, reaching epidemic levels in nontreated plots (Figs. 1 and 2, respectively, column A) and in plots with 14-day application intervals of the fungicide in all experiments (Figs. 1 and 2, respectively, column B). Late blight was detected in Jacqueline Lee only at negligible levels in all plots (including nontreated plots) at the end of the growing season in the three locations (data not shown).

Simulation. As a result of the calibration process, new LGR and SR parameters were generated for both Cal White and Granola (Table 2), whereas the LP used for both cultivars grown in Nicaragua was identical to that for Peruvian Tomasa. Both LGR and SR values derived for $\mathrm{Cal}$ White and Granola were somewhat lower than those of Tomasa (Table 2), thus indicating that, in theory, they are slightly more resistant than Tomasa

The simulation model generally predicted high disease severity in the absence of fungicide application, and demonstrated a decrease in the disease progress curves with additional fungicide applications, approximately similar to the observed data (Figs. 1 and 2). Based on this visual assessment, we concluded that the epidemic model and fungicide submodel were generally applicable to Nicaraguan conditions. To further assess the appropriateness of the model to predict fungicide efficacy, only false positives as defined above could be evaluated because fungicide failed to protect the cultivars sufficiently. However, given this limitation, the simulation model worked adequately in all epidemics except four in Tisey (2007), where it predicted improved and sufficient control (i.e., disease under 20\%) when this failed to occur. In all other cases, the model predicted that fungicide as applied would not be sufficient for adequate disease control. It should also be noted that the times when the model predicted wrongly were also when observed disease severity was lowest and when simulated disease initiated later than observed disease (Figs. 1 and 2).

However, the model did not perform well based on the more stringent EAT test, because only 15 of 40 epidemics were within the boundaries of the envelope (Fig. 3). By evaluating the performance of the model relative to disease severity in cultivar-year combinations, it was clear that there was a strong year effect and prediction occurred better in 2008 (Fig. 3). This effect was also evident when simulated AUDPC values were regressed on observed AUDPC values separately for years 2007 and 2008. The intercept was not significantly different from 0 , although it was slightly below 0 in 2007 and above 0 in 2008. In each year, the slope was significantly greater than 1 , with 1.28 in 2007 and 1.40 in 2008, suggesting a systematic error. Precision was similar both years because the $R^{2}$ was 0.76 in each case (Fig. 4).

Cultivar and fungicide effects. Based on mean observed RAUDPC for nontreated plots, Granola was only slightly less susceptible than Cal White and the difference was significant $(\alpha=$ 0.05 ) (Table 3 ) in only two experiments. When the RAUDPC was converted to susceptibility scale values, the two susceptible cultivars were generally within one scale value (Cal White was assigned a value of 8). The only clear exception was Miraflor-2007, where Granola had a value of 5.9. For Jacqueline Lee, calculation of scale values was consistent with a hypothesis of hypersensitivebased resistance, because a value of 0 was derived in each experiment (Table 3). Using visual assessment of disease progress curves and a $20 \%$ cut-off for final disease severity, no fungicide treatments, including fungicide application at 4-day intervals, were found to be adequate for managing the disease in the susceptible cultivars in any of the experiments (Figs. 1 and 2).

There was a clear and generally linear reduction in the observed AUDPC relative to the number of applications up through the 7day intervals, which was equal to nine applications (Fig. 5A). The additional six applications of the 4-day intervals did not appear to 
give the same relative decrease in the AUDPC and this was reflected in a curvilinear relationship, which was slightly better fit by a quadratic than a linear model. The relationship between the AUDPC and the number of sprays was similar in both 2007 and 2008 (Fig. 5A). The relationship between AUDPC and fungicide applications was generally similar for simulated data (Fig. 5B), although the curvilinearity between the two variables was less evident and less consistent between years.

\section{Discussion}

The simulation model was generally predictive but the degree of predictability depended on the type of evaluation measure used. Based simply on its ability to predict fungicide efficacy, it would appear to work reasonably well; therefore, we conclude that it is adequate for exploring general aspects of fungicide efficacy under Nicaraguan conditions. This is substantiated by the fact that the model produced disease progress curves that followed a pattern similar to those from observed severity data (i.e., regular decline in disease intensity associated with increasing fungicide use; Figs. 1 and 2). As a more specific case of this type of predictability, the model successfully indicated that, in general, frequent sprays of chlorothalonil would not be sufficient to control disease in susceptible cultivars under the prevailing environmental conditions. This outcome (lack of control) was not anticipated at the beginning of the trial but is consistent with a recent report from the Andes (22). It should be noted that, by increasing fungicide usage in the
A
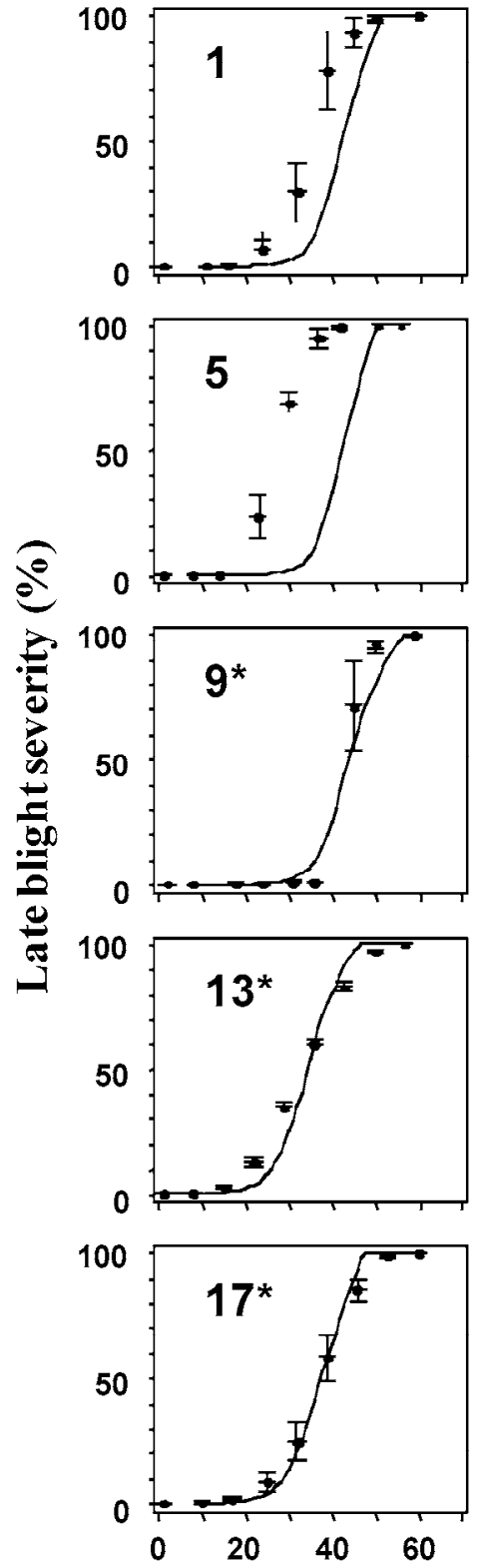

B
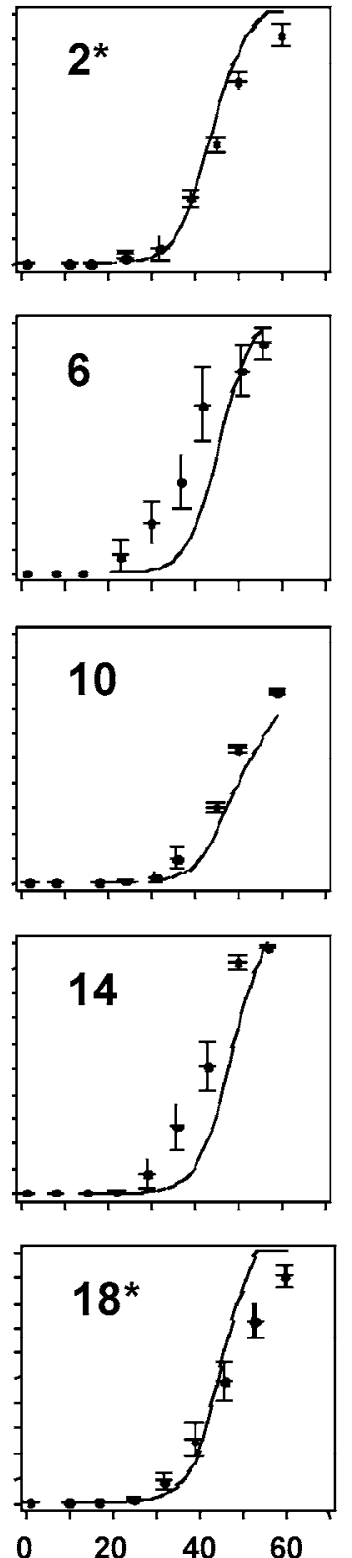

C
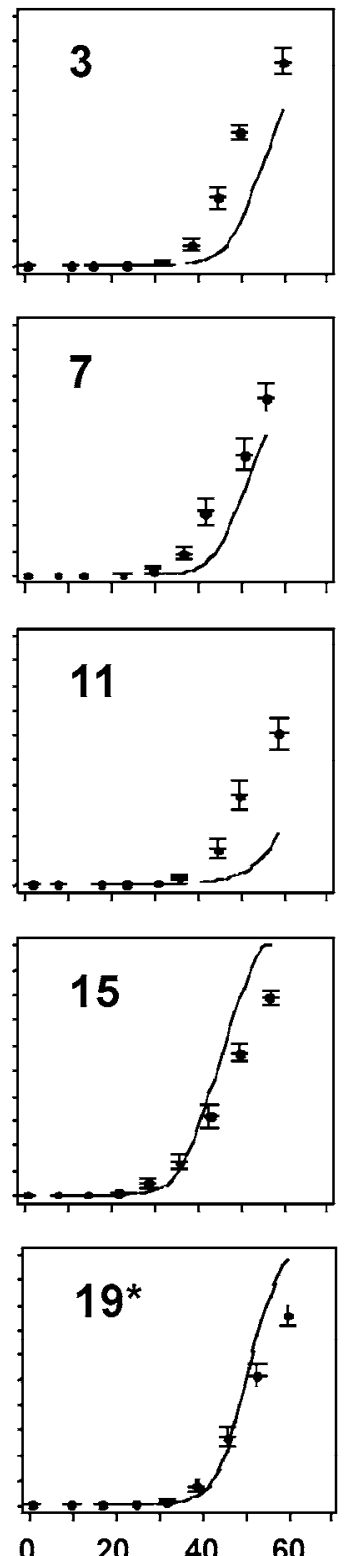

D
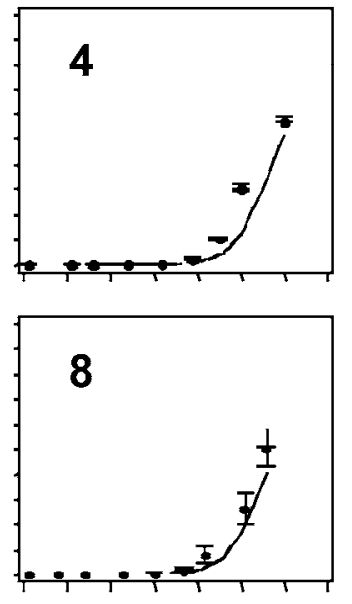

12
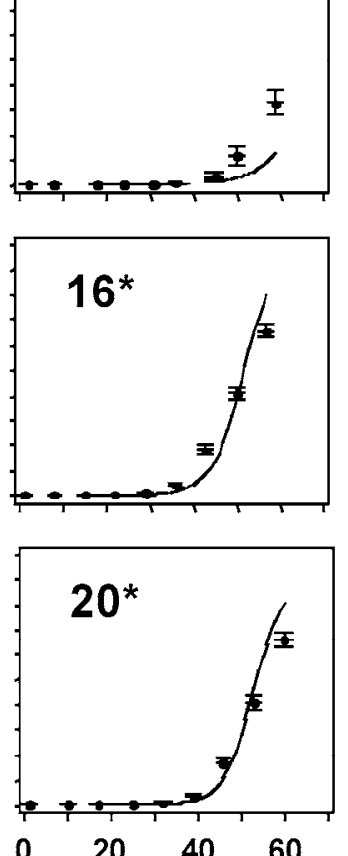

\section{Days after crop emergence}

Fig. 1. Observed (circles) and simulated (continuous line) disease progress curves for susceptible potato 'Cal White' in five field experiments carried out in three locations in Nicaragua during 2007 (epidemics 1 to 12) and 2008 (epidemics 13 to 20). Epidemics by locations were distributed as follow: Arenal 2007 (epidemics 1 to 4 ), Miraflor 2007 (epidemics 5 to 8), Tisey 2007 (epidemics 9 to 12), Miraflor 2008 (epidemics 13 to 16), and Tisey 2008 (epidemics 17 to 20). Columns represent fungicide application regimes: $A=$ no fungicide and $B, D$, and $D=14-, 7-$, and 4-day spray intervals, respectively. The epidemic number with asterisk indicates that area under the disease progress curve (AUDPC) deviations (mean AUDPC $_{\text {sim }}$ - mean AUDPC $_{\text {obs }}$ ) fell within the envelope of acceptance test. Vertical lines represent the standard deviation of the observed mean blight severity. 
model (higher dosage or more frequent sprays), we could predict adequate disease control (data not shown). This is a hypothesis that could be tested in subsequent field trials, although more frequent application is probably not practical for most potato farmers. Model adequacy was also demonstrated by an overall correlation between simulated and observed AUDPC values which was present both years (Fig. 4).

When model performance was assessed using the EAT, it did not perform as well as in a previously published study. Andrade-Piedra et al. (3) found that over $75 \%$ of epidemics they studied in Peru fell within the EAT, which was a higher percentage than identified in this study (Fig. 3). However, it is important to note that the earlier study only focused on nontreated plots and did not involve the fungicide submodel. Tedeschi (32) indicated that model appro- priateness should depend on its primary use. We intended to use the model to explore fungicide efficacy and, for that purpose, the model was adequate.

If models represent what we know about a biological system, then their inaccuracy can help identify knowledge gaps. In spite of general predictive capacity, the model also had systematic bias, as evidenced by the regression of simulated AUDPCs on observed. The slope of the line was greater than one in each year; the model tended to underpredict at low disease levels and overpredict at higher levels. A previous study indicated that the epidemic model in LB2004 is generally accurate over a wide range of environments with variable amounts of late blight severity (1); thus, we hypothesize that the bias is most likely occurring in the fungicide submodel, which has been used for the first time in this study. How-
A

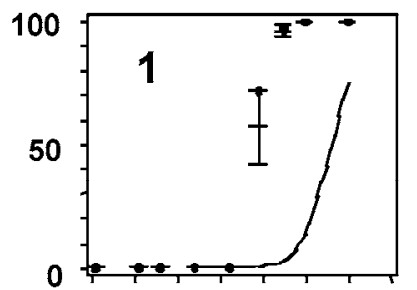

00
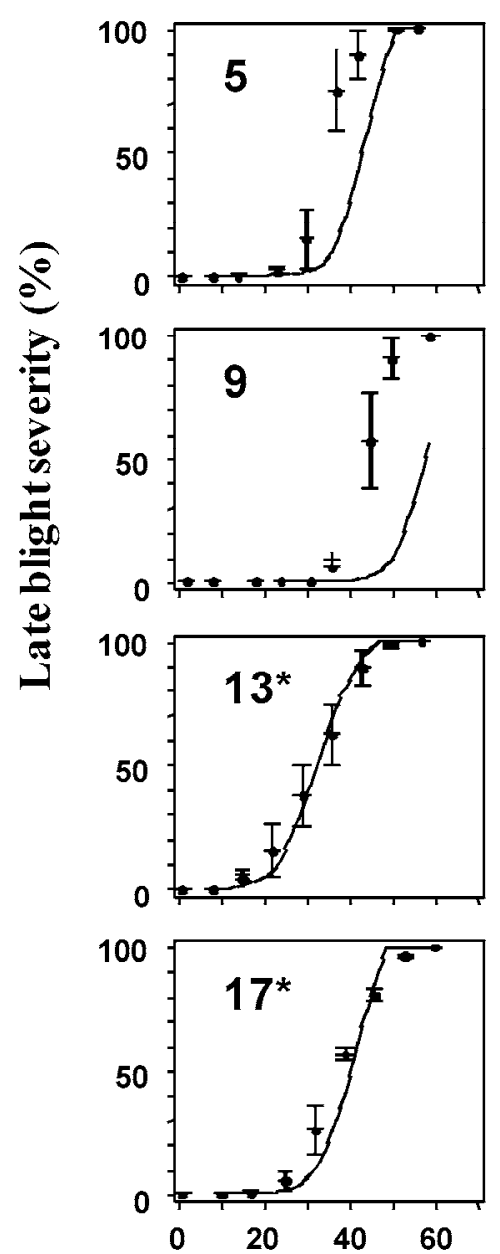

B
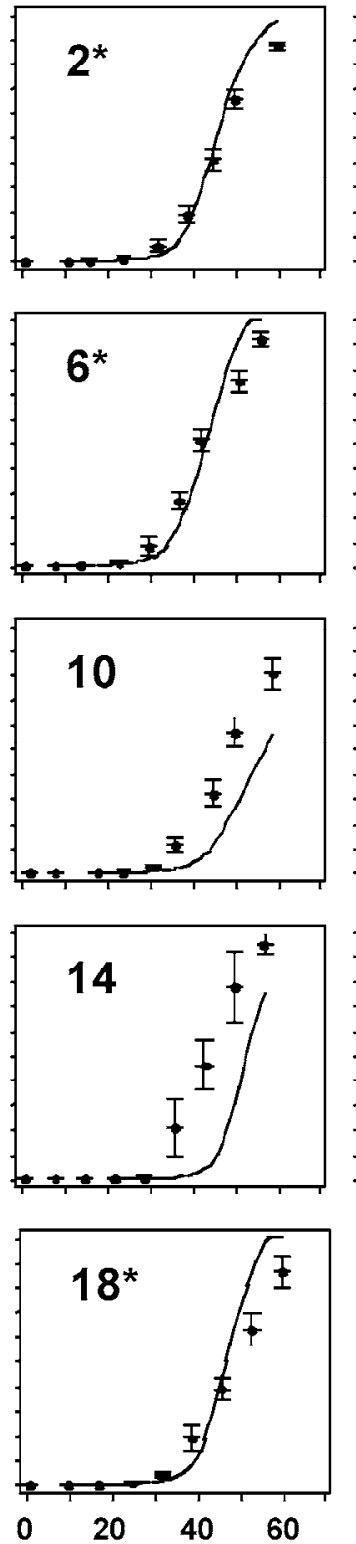

C
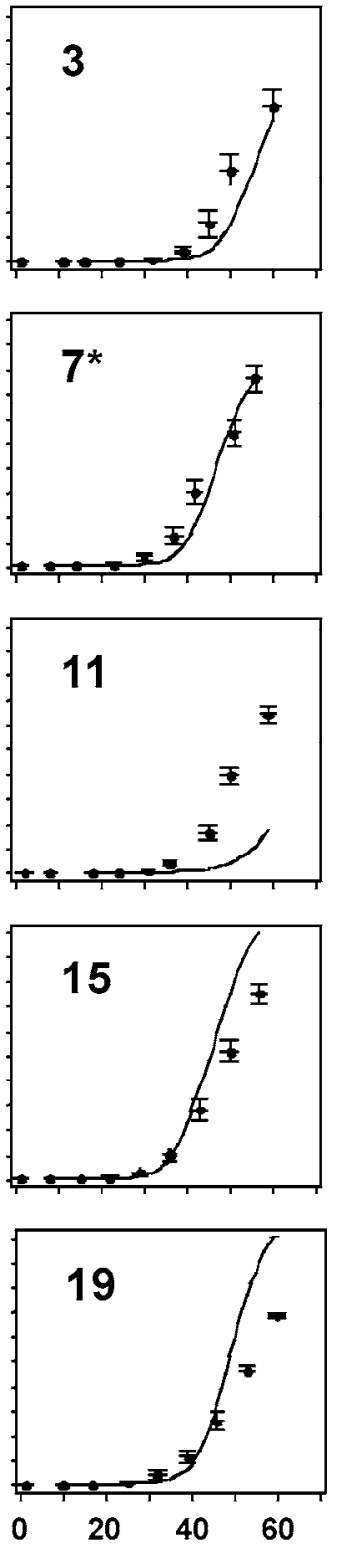

D
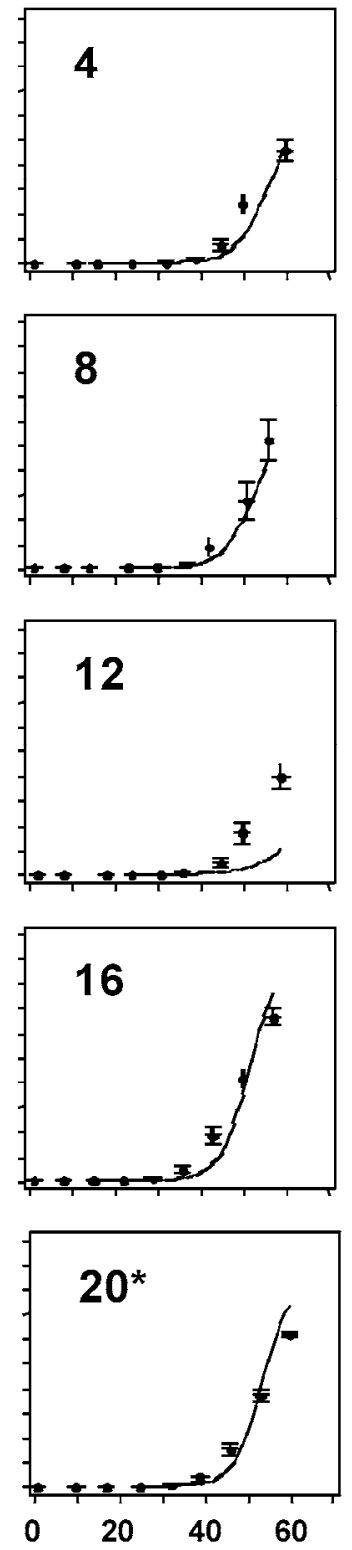

\section{Days after crop emergence}

Fig. 2. Observed (circles) and simulated (continuous line) disease progress curves for susceptible potato 'Granola' in five field experiments carried out in three locations in Nicaragua during 2007 (epidemics 1 to 12) and 2008 (epidemics 13 to 20). Epidemics by locations were distributed as follow: Arenal 2007 (epidemics 1 to 4 ), Miraflor 2007 (epidemics 5 to 8), Tisey 2007 (epidemics 9 to 12), Miraflor 2008 (epidemics 13 to 16), and Tisey 2008 (epidemics 17 to 20 ). Columns represent fungicide application regimes: $A=$ no fungicide and $B, D$, and $D=14-, 7-$, and 4-day spray intervals, respectively. The epidemic number with asterisk indicates that area under the disease progress curve (AUDPC) deviations (mean AUDPC $_{\text {sim }}$ - mean AUDPC $_{\text {obs }}$ ) fell within the envelope of acceptance test. Vertical lines represent the standard deviation of the observed mean blight severity. 
ever, some systematic error in the epidemic model may have also occurred.

We speculate on several areas where the model may be inaccurate, because they highlight future research needs. First, the model was developed in the temperate zone and was validated in systems in which diseases initiated approximately 50 days (10) after planting. In our study, disease initiated between 30 and 40 days after planting and thus, presumably, on smaller plants. At this growth stage, plants are increasing the proportion of new (and unprotected) tissue at a high rate and the model may not accurately estimate this proportion. Another potential source of error is that some equations in the fungicide submodel related to fungicide weathering were developed with older formulations of chlorothalonil and may not be accurate for the formulation used in the current study. Inaccuracy of both the epidemic and fungicide submodel could also result from the estimation of the time and amount of initial infection. We used the methodology developed by Andrade-Piedra et al. (2) for initiating epidemics in the simulation process but even this approach is based on observed infection, which can be very difficult to estimate at the beginning of the season. Small errors in estimation of initial infection can have large effects in the simulator results (1). Thus, the fact that the worst simulator performance was in Tisey (2007), when observed disease initiation was ex-

Table 2. Epidemiological parameters for potato 'Cal White' and 'Granola' used to validate the late blight simulation model LB2004 in five field experiments in three locations in Nicaragua during 2007 and 2008

\begin{tabular}{lllll}
\hline & \multicolumn{2}{c}{ Cultivars grown in Nicaragua } & & \multicolumn{2}{c}{$\begin{array}{c}\text { Peruvian } \\
\text { cultivar }\end{array}$} \\
\cline { 2 - 3 } \cline { 5 - 5 } Parameters $^{\mathbf{y}}$ & Cal White & Granola & & Tomasa $^{\mathbf{z}}$ \\
\hline LP & 2.82 & 2.82 & & 2.82 \\
LGR & $3.88\left(10^{-3}\right)$ & $3.70\left(10^{-3}\right)$ & & $4.1\left(10^{-3}\right)$ \\
SR & $4.10\left(10^{7}\right)$ & $4.30\left(10^{7}\right)$ & & $2.92\left(10^{8}\right)$ \\
\hline
\end{tabular}

${ }^{y} \mathrm{LP}=$ latent period (days); $\mathrm{LGR}=$ lesion growth rate (m/day), determined for Cal White and Granola by calibration; and SR = sporulation rate (sporangia/ $/ \mathrm{m}^{2} / \mathrm{day}$ ), determined for $\mathrm{Cal}$ White and Granola by calibration.

${ }^{z}$ Parameters for Tomasa (susceptible) were used by Andrade et al $(2,3)$ in the development and validation of the model version LB2004; the parameters were used directly (LP) for Cal White and Granola or as a starting point for calibration (LGR and SR). tremely late, is possibly related to the problem of accurately estimating the initiation of disease. Based on the performance of the simulator, one could hypothesize that disease initiated somewhat earlier in Tisey (2007) than was estimated by the field observers. This also appeared to be the case for a couple of epidemics of Granola in Arenal (2007), when the simulator predicted more disease with additional fungicide (Fig. 2, compare plots 1 and 2 and plots 14 and 15). Because the observed data did not demonstrate a similar pattern, we assume that there was inaccuracy in the initiation of disease for the simulation process.

In this study, we also did not have measured parameters for the susceptible Cal White and Granola; thus, we used the calibration

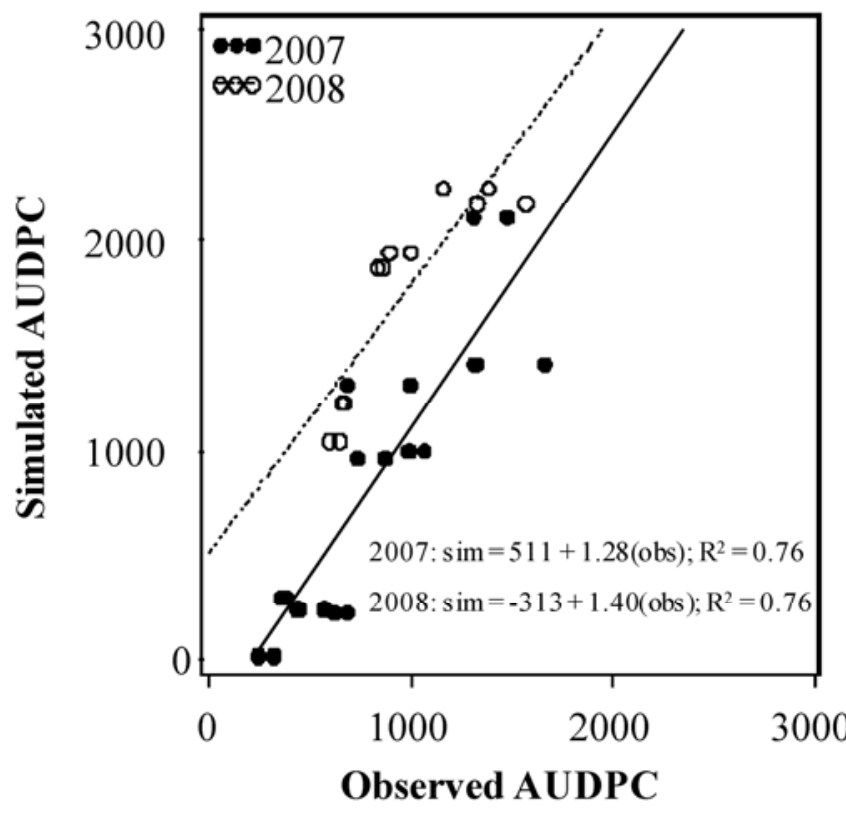

Fig. 4. Regression of simulated area under the disease progress curve (AUDPC) values on and observed AUDPC values for late blight severity on two susceptible potato cultivars ('Cal White' and 'Granola') grown in Nicaragua during 2007 and 2008. Note that the precision was similar both years because the $R^{2}$ was 0.76 in each case.

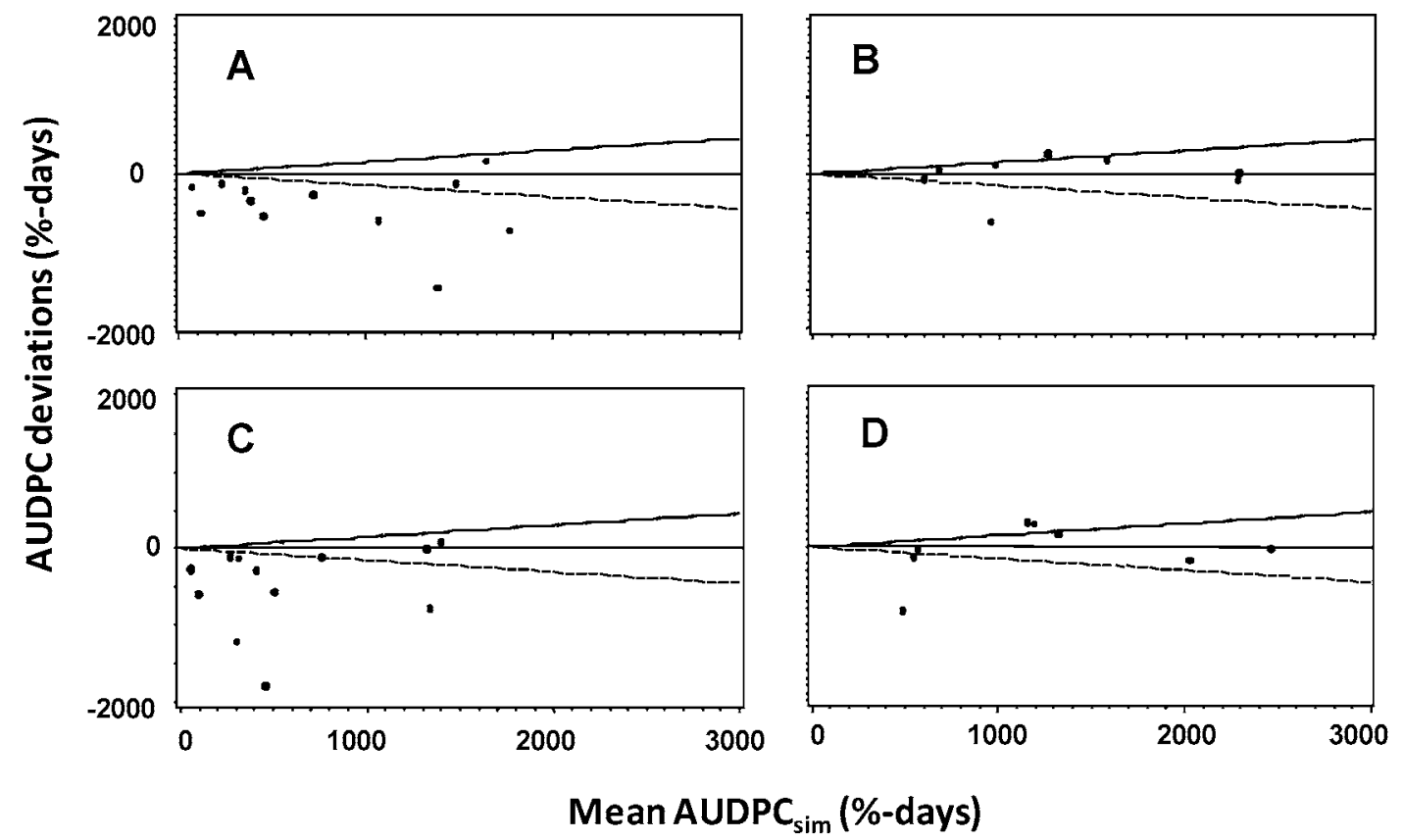

Fig. 3. Performance of late blight simulation model LB2004 based on the envelope of acceptance test (EAT) involving susceptible 'Cal White' during A, 2007 and B, 2008 and 'Granola' during C, 2007 and D, 2008; each cultivar was evaluated with no fungicide protection and three fungicide spray regimes (14-, 7-, and 4-day spray intervals) in five field experiments carried out in Nicaragua. Each dot in the graphs represents an epidemic (year-location-cultivar-spray combination). 
process described earlier. Greenhouse and phytotron facilities were not available for accurate measurements of these parameters. Nonetheless, Andrade-Piedra et al (1) found that the model was more sensitive to accurate estimation of initial inoculum than to resistance parameters and we also assume that inaccuracy in resistance parameters would have uniformly affected fungicide treatments. The parameters derived for Cal White and Granola represent a level of resistance slightly higher than that of Tomasa. This, then, is another hypothesis that could be evaluated in a field trial and would serve as a partial test of the role of resistance parameters in the overall predictiveness of the model.

Based on the reaction of Jacqueline Lee, we concluded that this cultivar was protected in all experiments, at least for most of the season, by an effective $R$ gene. However, the $R$ genes present in Jacqueline Lee did not confer it complete immunity, because low levels of infection were observed at the end of the growing season. Andrivon et al. (5) published a method for determining the presence of $R$-gene-mediated resistance based on disease appearance and consequent apparent infection rates. Lack of disease was considered to be indication of effective $R$ genes. Recently, Andreu et al. (4) also deduced $R$ gene phenotypes in field experiments but were not able to apply the approach of Andrivon et al. (5).

For the other two cultivars, the results indicated that even 4-day application intervals with the contact fungicide chlorothalonil would not control disease in any of the locations. This result is consistent with the conclusions of Kromann et al. (22), who also recently reported that susceptible cultivars could not be controlled with frequent (approximately weekly) applications of contact fungicides in the highlands of Peru and Ecuador. The lack of control with frequent contact sprays in tropical and subtropical conditions may result, at least in part, from the very early initiation of disease during a period when the proportion of new plant growth per day is great. Furthermore, because spraying was initiated near $50 \%$ emergence, new, unprotected plants were emerging daily and may have been exposed to incoming inoculum; this could also have compromised the protection afforded by the fungicide.

In our study, simultaneous experiments with systemic and contact fungicides to compare their respective effectiveness were not conducted. Nevertheless, it would seem that use of more effective systemic or translaminar fungicides would be a logical alternative for improving management of late blight in this system, as in other systems (22,31). This would appear to be true for the Central American and Andean highlands but may also be true for other tropical highland locations. The $20 \%$ cut-off we used for determining fungicide efficacy was also used by Kromann et al. (22); however, it was the "best guess" used for comparative purposes and is not derived from experimental data and does not constitute an economic or action threshold.

In developing countries, including Nicaragua, potato growers rely on the readily available contact fungicides chlorothalonil and mancozeb. Nonetheless, our study demonstrated a lack of adequate fungicide protection with chlorothalonil on Cal White and Granola, which indicates the need for cultivars with higher levels of durable resistance. In their absence, farmers should consider more effective

Table 3. Host resistance to Phytophthora infestans of three potato cultivars ('Cal White', 'Granola', and 'Jacqueline Lee') grown in five trials in Nicaragua based on the relative area under the disease progress curve (RAUDPC) and a susceptibility scale

\begin{tabular}{|c|c|c|c|c|c|c|}
\hline \multirow[b]{2}{*}{ Location, year } & \multicolumn{2}{|c|}{ Cal White } & \multicolumn{2}{|c|}{ Granola } & \multicolumn{2}{|c|}{ Jacqueline Lee } \\
\hline & RAUDPC & Scale & RAUDPC & Scale & RAUDPC & Scale \\
\hline Arenal 2007 & $0.42 \mathrm{a}$ & 8 & $0.38 \mathrm{a}$ & 7.2 & $0.01 \mathrm{c}$ & 0 \\
\hline Miraflor 2007 & $0.52 \mathrm{a}$ & 8 & $0.38 \mathrm{~b}$ & 5.9 & $0.01 \mathrm{c}$ & 0 \\
\hline Tisey 2007 & $0.28 \mathrm{a}$ & 8 & $0.27 \mathrm{a}$ & 7.7 & $0.01 \mathrm{~b}$ & 0 \\
\hline Miraflor 2008 & $0.42 \mathrm{a}$ & 8 & $0.44 \mathrm{a}$ & 8.4 & $0.01 \mathrm{~b}$ & 0 \\
\hline Tisey 2008 & $0.39 \mathrm{a}$ & 8 & $0.37 \mathrm{a}$ & 7.6 & $0.01 \mathrm{~b}$ & 0 \\
\hline
\end{tabular}

${ }^{\mathrm{z}}$ RAUDPC values in the same row that are followed by different letters are statistically different at $P=0.05$ based on a least significant difference test. Susceptibility was based on an interval scale (33) in which values are derived from a common control cultivar; in this case, the control was Cal White, which was given a value of 8

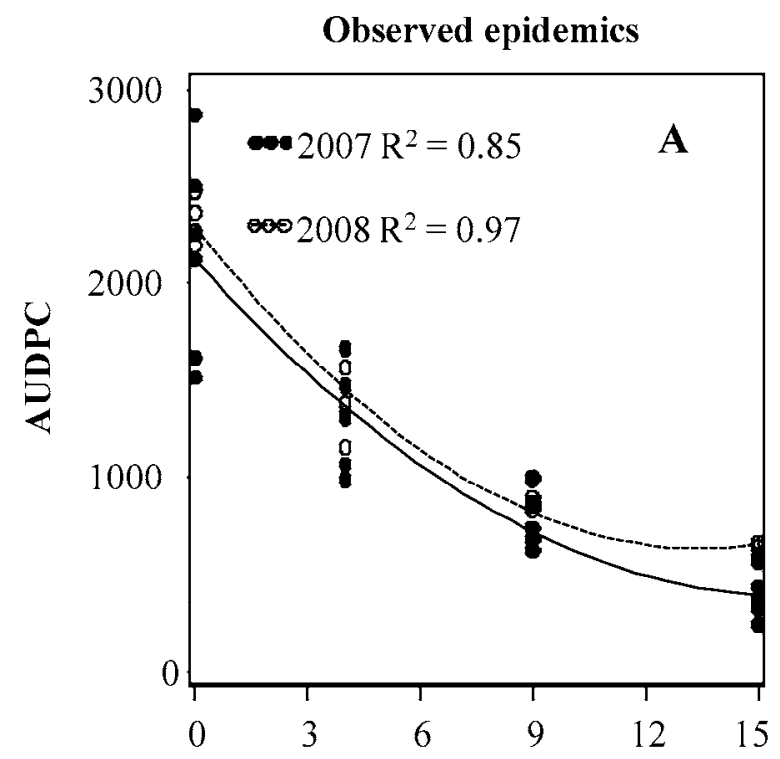

Fungicide sprays

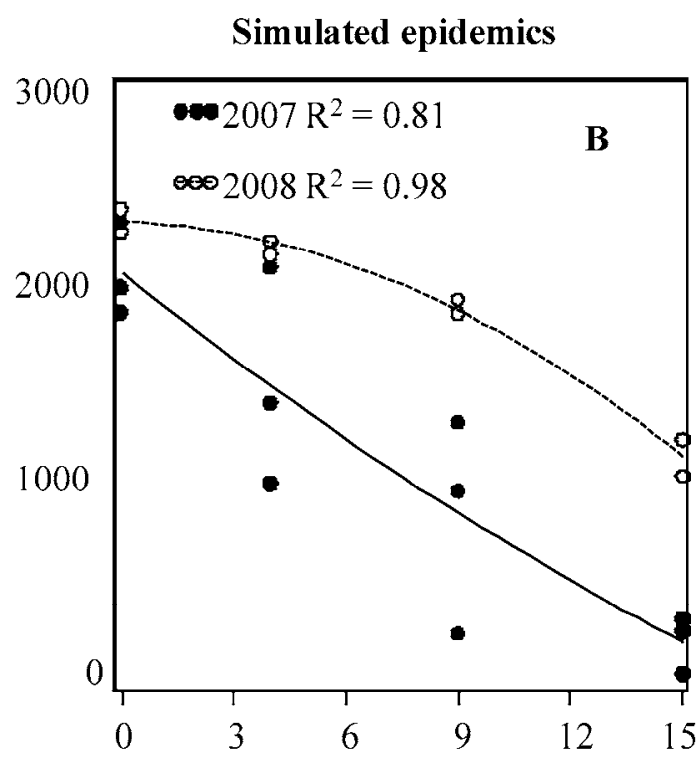

Fungicide sprays

Fig. 5. Relationship between the area under the disease progress curve (AUDPC) and number of fungicide sprays in 10 potato late blight epidemics from controlled field experiments implemented in northern Nicaragua in 2007-2008. Data are given for both A, observed and B, simulated epidemics. Data points represent two susceptible potato cultivars, 'Cal White' and 'Granola'. 
fungicide applications, involving either higher dosages or different chemistries, including systemic and translaminar products.

In addition to lack of control in this study, chlorothalonil and mancozeb have been identified as probable carcinogens (31). Therefore, the LB2004 simulation model should be modified to simulate the effects of other fungicides that pose a lower health or environmental risk, and are potentially more effective, including those with systemic or translaminar properties.

\section{Acknowledgments}

This research was supported by the Swedish International Development Cooperation Agency, Swedish Agency for Research Cooperation with Developing Countries, and Swedish Institute. We also thank the potato growers for access to their fields for trials.

\section{Literature Cited}

1. Andrade-Piedra, J. L., Forbes, G. A., Shtienberg, D., Grünwald, N. J., Chacón, M. G., Taipe, M. V., Hijmans, R. J., and Fry, W. A. 2005. Qualification of a plant disease simulation model: performance of the LATEBLIGHT model across broad range of environments. Phytopathology 95:1412-1422.

2. Andrade-Piedra, J. L., Hijmans, R. J., Forbes, G. A., Fry, W. E., and Nelson, R. J. 2005. Simulation of potato late blight in the Andes. I: modification and parameterization of the LATEBLIGHT model. Phytopathology 95:11911199.

3. Andrade-Piedra, J. L., Hijmans, R. J., Juárez, H. S., Forbes, G. A., Shtienberg, D., and Fry, W. E. 2005. Simulation of potato late blight in the Andes. II: validation of the LATEBLIGHT model. Phytopathology 95:1200-1208.

4. Andreu, A. B., Caldiz, D. O., and Forbes, G. A. 2010. Phenotypic expression of resistance to Phytophthora infestans in processing potatoes in Argentina. Am. J. Pot. Res. 87:177-187.

5. Andrivon, D., Pellé, R., and Ellissèche, D. 2006. Assessing resistance types and levels to epidemic diseases from the analysis of disease progress curves: principles and applications to potato late blight. Am. J. Pot. Res. 83:455-461.

6. Anonymous. 1947. The measurement of potato blight. Trans. Br. Mycol. Soc. 31:140-141

7. Avila-Adame, C., Gómez-Alpizar, L., Zismann, V., Jones, K. M., Robin Buell, C., and Ristaino, J. B. 2006. Mitochondrial genome sequences and molecular evolution of the Irish potato famine pathogen, Phytophthora infestans. Curr. Genet. 49:39-46.

8. Bruhn, J. A., Bruck, R. I., Fry, W. E., Arneson, P. A., and Keokosky, E. V. 1980. User's Manual for LATEBLIGHT: A Plant Disease Management Game. Mimeo 80-1. Cornell University, Department of Plant Pathology, Ithaca, NY.

9. Bruhn, J. A., and Fry, W. E. 1981. Analysis of potato late blight epidemiology by simulation modelling. Phytopathology 71:612-616.

10. Bruhn, J. A., and Fry, W. E. 1982. A statistical model of fungicide deposition in a potato canopy. Phytopathology 72:1301-1305.

11. Bruhn, J. A., and Fry, W. E. 1982. A mathematical model of the spatial and temporal dynamics of chlorothalonil residues in a potato canopy. Phytopathology 72:1306-1312.

12. Campbell, C. L., and Madden, L. V. 1990. Temporal analysis of epidemics I: description and comparison of disease progress curves. Pages 161-202 in: Introduction to Plant Disease Epidemiology. John Wiley \& Sons, New York.

13. Doster, M. A., Milgroom, M. G., and Fry, W. E. 1990. Quantification of factors influencing potato late blight suppression and selection for metalaxyl resistance in Phytophthora infestans: a simulation approach. Phytopathology 80:1190-1198.

14. Douches, D. S., Jastrzebski, K., Coombs, J., Kirk, W. W., Felcher, K. J., Hammerschmidt, R., and Chase, R. W. 2001. Jacqueline Lee: a late-blightresistant tablestock variety. Am. J. Pot. Res. 78:413-419.

15. Fry, W. E. 1977. Integrated control of potato late blight: effects of polygenic resistance and techniques of timing fungicide applications. Phytopathology 67:415-420.

16. Fry, W. E. 1978. Quantification of general resistance of potato cultivars and fungicide effects for integrated control of potato late blight. Phytopathology 68:1650-1655.

17. Fry, W. E., Grünwald, N. J. Cooke, D. E. L. McLeod, A. Forbes, G.A., and Cao, K. 2009. Population genetics and population diversity of Phytophthora infestans. Pages 139-164 in: Oomycete Genetics and Genomics: Biology, Interactions and Research Tools. K. Lamour and S. Kamoun, eds. WileyBlackwell, New York.

18. Fry, W. E., Milgroom, M. G., Doster, M. A., Bruhn, J. A., and Bruck, R. I. 1991. LATEBLIGHT: A Plant Disease Management Game: User's Manual. Version 3.1. Microsoft Windows adaptation by B. E. Ticknor and P. A. Arneson. Cornell University, Department of Plant Pathology, Ithaca, NY.

19. Grünwald, N. J., Romero Montes, G., Lozoya Saldaña, H., Rubio Covarrubias, O. A., and Fry, W. E. 2002. Potato late blight management in the Toluca valley: field validation of SimCast modified for cultivars with high field resistance. Plant Dis. 86:1163-1168.

20. Kamoun, S., and Smart, C. D. 2005. Late blight of potato and tomato in the genomics era. Plant Dis. 89:692-699.

21. Kirk, W. W., Abu-El Samen, F. M., Muhinyuza, J. B., Hammerschmidt, R. Douches, D. S., Thill, C. A., Groza, H., and Thompson, A. L. 2005. Evaluation of potato late blight management utilizing host plant resistance and reduce rates and frequencies of fungicide applications. Crop Prot. 24:961 970 .

22. Kromann, P., Taipe, A., Perez, W. G., and Forbes, G. A. 2009. Rainfall thresholds as support for timing fungicide applications in the control of potato late blight in Ecuador and Peru. Plant Dis. 93:142-148.

23. Mitchell, P. L. 1997. Misuse of regression for empirical validation of models. Agric. Syst. 54:313-326.

24. Ortiz, O., Garrett, K. A., Heath, J. J., Orrego, R., and Nelson, R. J. 2004. Management of potato late blight in the Peruvian highlands: evaluating the benefits of farmer field schools and farmer participatory research. Plant Dis. 88:565-571.

25. Oyarzún, P. J., Garzón, C. D., Leon, D., Andrade, I.., and Forbes, G. A 2005. Incidence of potato tuber blight in Ecuador. Am. J. Potato Res. $82: 117-122$

26. Quinn, G. P., and Keough, M. J. 2009. Experimental Design and Data Analysis for Biologists, Eighth ed. Cambridge University Press, New York.

27. SAS Institute Inc. 2004. SAS/STAT 9.1 User's Guide. SAS Institute Inc., Cary, NC.

28. Sherwood, S. 2009. Learning from Carchi: agricultural modernization and the production of decline. Ph.D. dissertation, Wageningen University and Research Centre, Wageningen, The Netherlands.

29. Shtienberg, D., Doster, M. A., Pelletier, J. R., and Fry, W. E. 1989. Use of simulation models to develop a low-risk strategy to suppress early and late blight in potato foliage. Phytopathology 79:590-595.

30. Shtienberg, D., and Fry, W. E. 1990. Field and computer simulation evaluation of spray scheduling methods for control of early and late blight of potato. Phytopathology 80:772-777.

31. Stein, J. M., and Kirk, W. W. 2003. Field optimization of dimethomorph for the control of potato late blight Phytophthora infestans: application rate, interval and mixtures. Crop Prot. 22:609-614.

32. Tedeschi, L. O. 2006. Assessment of the adequacy of mathematical models Agric. Syst. 89:225-247.

33. United States Potato Board. 2007. Guide to U.S. Seed Potato Export Varieties. U.S.P.B., Denver.

34. van Haren, R. J. F., and Jansen, D. M. 1999. LINBAL, light interception by active layers-description and application of a water, nitrogen and late blight limited potato growth model for the Andean ecoregion. Note 16. Plant Research International, Wageningen, The Netherlands.

35. Yuen, J. E., and Forbes, G. A. 2009. Estimating the level of susceptibility to Phytophthora infestans in potato genotypes. Phytopathology 99:782-786. 